\title{
Sensitivity and specificity of ultrasound in the diagnosis of acute appendicitis
}

Y. Al-Ajerami ${ }^{1}$

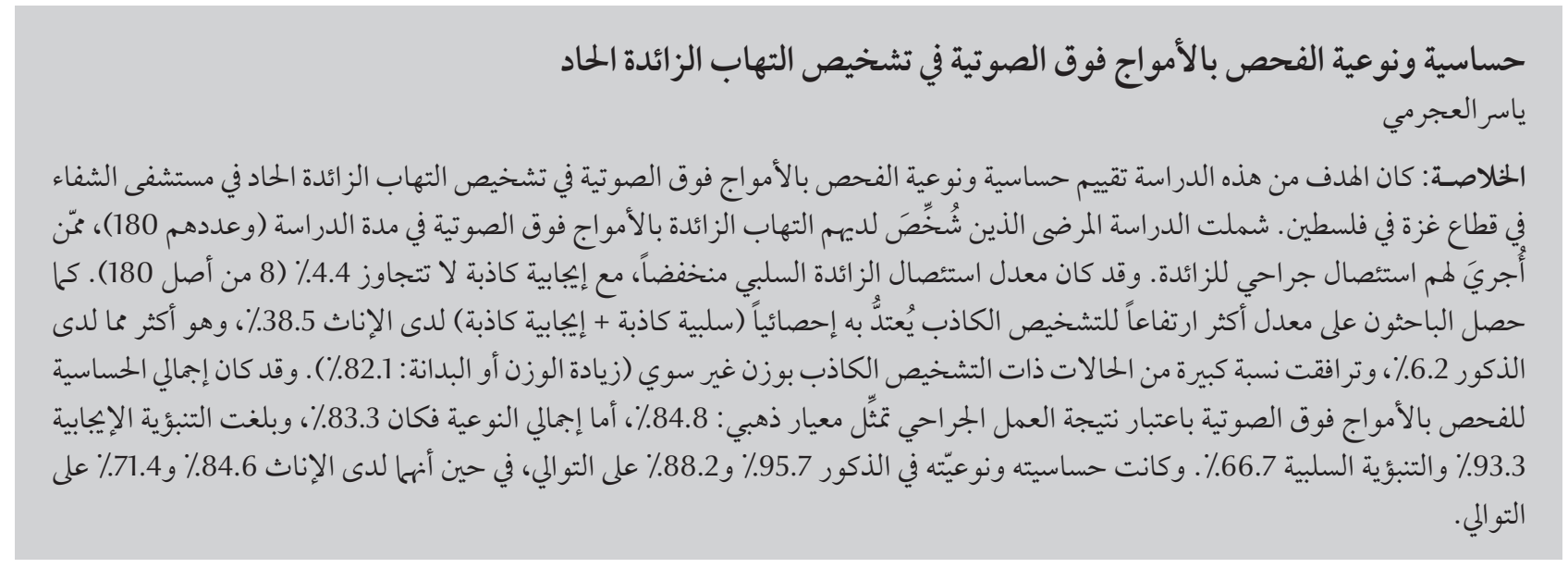

ABSTRACT The aim of this study was to evaluate the sensitivity and specificity of ultrasound in the diagnosis of acute appendicitis at Al-Shefa hospital, Gaza Strip, Palestine. Patients who had appendicitis diagnosed by ultrasound over the study period $(n=180)$ underwent surgical excision of the appendix. The negative appendectomy rate was low, with only 4.4\% (8/180) false positives. A significantly higher false diagnosis rate (false negatives + false positives) was obtained in female patients than in males: $38.5 \%$ versus $6.2 \%$. A high proportion of falsely diagnosed cases had abnormal weight (overweight or obese) (82.1\%). The overall sensitivity and specificity of ultrasound, using surgical outcome as the gold standard, were $84.8 \%$ and $83.3 \%$ respectively, and the positive and negative predictive values were $93.3 \%$ and $66.7 \%$ respectively. Sensitivity and specificity were higher in males (95.7\% and $88.2 \%$ respectively) than females ( $84.6 \%$ and $71.4 \%$ respectively).

\section{Sensibilité et spécificité de l'examen échographique pour le diagnostic de l'appendicite aiguë}

RÉSUMÉ La présente étude visait à évaluer la sensibilité et la spécificité de l'examen échographique pour le diagnostic de l'appendicite aiguë à I'hôpital Al-Shifa situé dans la Bande de Gaza (Palestine). L'appendice a été excisé chez les patients $(n=180)$ chez qui une appendicite a été diagnostiquée après un examen échographique réalisé pendant la période de l'étude. Le taux d'appendicectomies blanches était faible, avec un taux de faux positifs de seulement 4,4\% (8 cas sur 180). Le taux de diagnostics erronés (faux négatifs + faux positifs) était nettement supérieur chez les patientes que chez les patients : 38,5\% par rapport à 6,2\%. Une proportion élevée $(82,1 \%)$ de patients ayant reçu un diagnostic erroné présentait un surpoids ou souffrait d'obésité. En prenant le résultat de l'intervention chirurgicale comme critère de référence, la sensibilité de l'examen échographique était de $84,8 \%$, sa spécificité de 83,3\%, et les valeurs prédictives positives et négatives s'élevaient à 93,3 \% et 66,7 \% respectivement. La sensibilité et la spécificité de l'examen échographique étaient supérieures chez les hommes (95,7 \% et 88,2\% respectivement) que chez les femmes (84,6 \% et 71,4\% respectivement).

'Medical Radiography Department, Faculty of Applied Medical Sciences, Al-Azhar University, Gaza Strip, Palestine (Correspondence to Y. AlAjerami Yasser_ajr@hotmail.com).

Received: 10/01/10; accepted: 09/06/10 


\section{Introduction}

Acute appendicitis is one of the most common acute conditions requiring urgent abdominal surgery in both adults and children $[1,2]$. It is a common cause of right lower quadrant pain. The current annual incidence of acute appendicitis in the Gaza Strip is 15 cases per 100000 populations [3]. Severe complications result from perforation of acute appendicitis, generally resulting from delayed diagnosis. Hence, a surgical intervention will be the first priority for the surgeons.

Early diagnosis of appendicitis is still a challenge [4]. During the last decade, use of white blood cell scans and ultrasound and computerized tomography (CT) scanning have improved the diagnostic accuracy for acute appendicitis $[5,6]$. Despite the use of ultrasound and special laboratory investigations (e.g. C-reactive protein), high diagnostic error rates are still observed [7]. The negative appendectomy rate in large series ranged from $15 \%$ to $33 \%[8,9]$. In patients with atypical history or equivocal physical examination findings, particularly in women of childbearing age, the negative appendectomy rate may be as high as $45 \%$ [10].

The diagnosis of acute appendicitis by ultrasound has been used since the 1980s. Its benefits include low cost, safety (no ionizing radiation) and the ability to provide dynamic information [8]. Previous studies, however, have found that the accuracy of ultrasound is less than that of CT [11-14]. This study at a hospital in Gaza Strip aimed to evaluate the accuracy of ultrasound in the diagnosis of acute appendicitis.

\section{Methods}

\section{Sample}

The study was carried out at Al-Shefa hospital, Gaza Strip, Palestine. Between 3 April 2008 to 30 July 2008, 180 patients who were clinically diagnosed with appendicitis by both physical examination and laboratory tests were selected for ultrasound examination. All patients diagnosed with appendicitis over the study period were selected for the study regardless of age or sex. Patients with a history of malignancy, congenital anomaly and pregnant women were excluded. Approval for the study was obtained from the Palestinian Ministry of Health. The subjects who participated in the study were asked to sign an informed consent form.

\section{Data collection}

The age, sex and body mass index (BMI) of the patients were recorded.

Ultrasound images were obtained using the Toshiba Nemio XG with PVM 375AT probe and prospectively interpreted by at least 2 different radiologists. Although a $7.5 \mathrm{MHz}$ probe with an annular array transducer was generally used, a $5 \mathrm{MHz}$ convex probe was also employed depending on the patient's physique and the depth of the appendix. On the basis of ultrasonograph findings, appendicitis was classified as follows: catarrhal (appendix was tubular with a clear layer structure of the appendiceal wall, slight mucosal oedema, and a maximum transverse diameter of $10 \mathrm{~mm}$ ); phlegmonous (ill-defined layer structure of the appendix wall, moderate enlargement of the appendix, and a maximum transverse diameter of $10 \mathrm{~mm}$ ); gangrenous (illdefined or unidentifiable layer structure of the appendiceal wall and severe enlargement of the appendix to form a mass) [13].

Patients who had appendicitis diagnosed by ultrasound also underwent CT scanning and then surgical excision of the appendix. The patients were followed up after surgery to determine the number of true positive, true negative, false positive and false negative ultrasound findings based on the surgical report as the gold standard.

\section{Data analysis}

The data were tabulated, encoded and analysed using SPSS, version 13 . The chi-squared test was used to determine whether the difference in frequency (percentage) among the same groups was significant or not.

\section{Results}

A total of 128 males (71.1\%) and 52 females $(28.9 \%)$, with a mean age of 20 years (range 5-51 years), underwent appendectomy. Table 1 shows the distribution of patients by age, sex and BMI category; $86.7 \%$ of males and $80.7 \%$ of females were over 10 years old and $34.4 \%$ of males and $46.2 \%$ of females

\begin{tabular}{lrrrrrr}
\hline $\begin{array}{l}\text { Table 1 Distribution of patients by age, sex and body mass index (BMI) category } \\
\text { Variable }\end{array}$ & \multicolumn{3}{c}{ Males } & \multicolumn{2}{c}{ Females } & \multicolumn{2}{c}{ Total } \\
& No. & $\%$ & No. & $\%$ & No. & $\%$ \\
$\begin{array}{l}\text { Age group (years) } \\
<11\end{array}$ & 17 & 13.3 & 10 & 19.2 & 27 & 15.0 \\
$11-20$ & 41 & 32.0 & 11 & 21.2 & 52 & 28.9 \\
$21-30$ & 41 & 32.0 & 10 & 19.2 & 51 & 28.3 \\
$31-40$ & 17 & 13.3 & 8 & 15.4 & 25 & 13.9 \\
$>40$ & 12 & 9.4 & 13 & 25.0 & 25 & 13.9 \\
BMI category & & & & & & \\
$\quad$ Normal & 84 & 65.6 & 28 & 53.8 & 112 & 62.2 \\
$\quad$ Overweight & 16 & 12.5 & 16 & 30.8 & 32 & 17.8 \\
$\quad$ Obese & 28 & 21.9 & 8 & 15.4 & 36 & 20.0 \\
Total & 128 & 100.0 & 52 & 100.0 & 180 & 100.0 \\
\hline
\end{tabular}




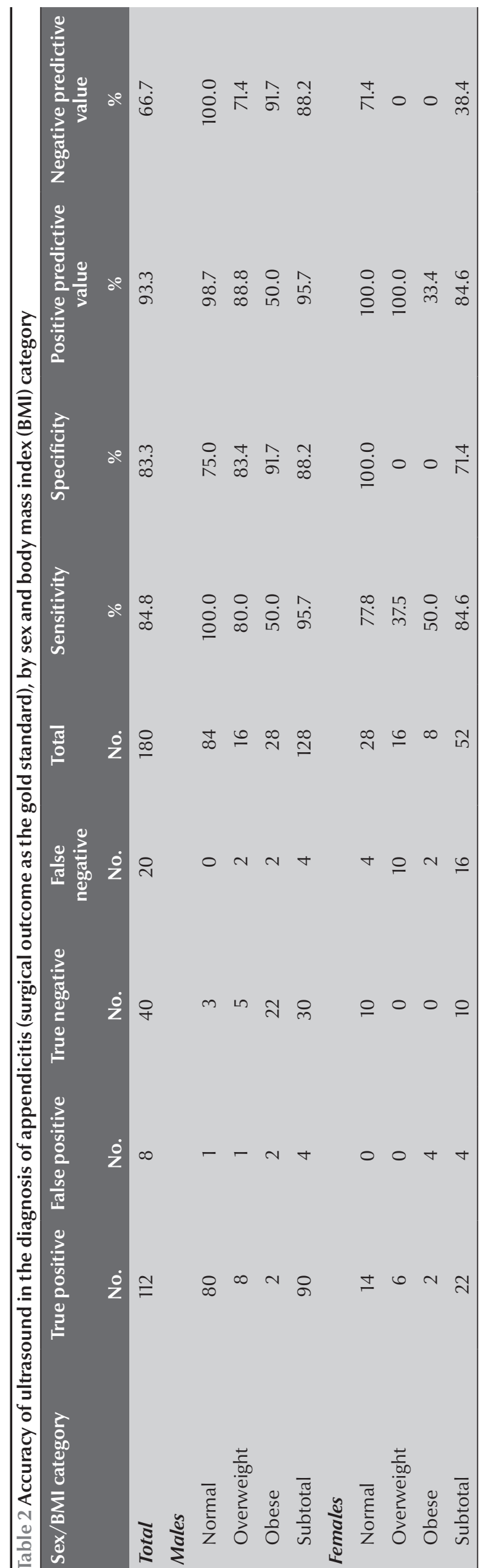

were obese or overweight. The highest rate of acute appendicitis in this sample was found in the age group 11-20 years (28.9\%).

The great majority of males with appendicitis (86.7\%) presented with right lower quadrant pain, raised white blood cell counts, fever and vomiting compared with only $13.5 \%$ of females.

Table 2 shows the accuracy of ultrasound for the diagnosis of appendicitis for all patients and by BMI category and sex. Overall there were $8 / 180$ false positives, giving a negative appendectomy rate of $4.4 \%$. There were $20 / 180$ patients who were false negatives (11.1\%). The sensitivity and specificity of ultrasound examination for all patients were $84.8 \%$ and $83.3 \%$ respectively and the positive and negative predictive values were $93.3 \%$ and $66.7 \%$ respectively (Table 2 ). The sensitivity and specificity of the test were higher in males (95.7\% and 88.2\% respectively) than females ( $84.6 \%$ and $71.4 \%$ respectively).

The total rate of false diagnosis by ultrasound (false negatives + false positives) was therefore 28/180 (15.6\%). A significantly higher false diagnosis rate was obtained in female patients than in males: $38.5 \%$ versus $6.2 \%$ $(P<0.001)$. A high proportion of the 28 falsely diagnosed cases $(23,82.1 \%)$ were overweight or obese ( 2 males and 18 females). CT scanning showed true positive results for appendicitis in $20 / 28$ patients $(71.4 \%)$ who had a false diagnosis by ultrasound (4 males and 16 females).

\section{Discussion}

Acute appendicitis remains one of the most common surgical emergencies with a lifetime occurrence of 7\% [10]. Early ultrasound detection and surgical intervention is the best way to manage acute appendicitis in order to reduce complications and mortality [11]. The incorrect diagnosis of acute appendicitis by ultrasound is due to many causes: ultrasound may not detect the appendix when it is retrocaecally located or if it lies deep in the pelvis; excess overlying bowel gas may also be problematic, Incorrect clinical diagnosis is affected by the experience of physicians and radiologists, the stage or degree of appendicitis and the sex, age and BMI of patients [12]. The negative appendectomy rate can be significantly reduced by using ultrasound coupled with clinical assessment and evaluation $[15,16]$.

Lewis et al. and Lee et al. found that the negative appendectomy rate was $15.7 \%$ and $16 \%$ respectively $[10,14$,$] . By compari-$ son, we had a low negative appendectomy rate, with only $4.4 \%$ false positives. Summa et al. found false positive results in only $7 / 308$ of cases $(2 \%)$ [17].

In our study, the accuracy of ultrasound examination varied with the age group and BMI category of patients. A significantly higher false diagnosis rate was obtained in female patients than in males: $38.5 \%$ versus $6.2 \%$. A similar difference was obtained by Paulson et al. and this may be related to gynaecological 
conditions simulating the signs of acute appendicitis [6]. The great majority of falsely diagnosed cases (82.1\%) had abnormally high weight (i.e. overweight or obese), slightly more in male patients (87.5\%) compared with female patients (80.0\%).

Lee et al. showed that the incidence of acute appendicitis increased in patients younger than 10 years and older than 50 years [14]. The highest rate of acute appendicitis in our sample was found in the age group 11-20 years.
In this study, in spite of the viability of ultrasound examination to detect and diagnose acute appendicitis in approximately $84.8 \%$ of cases, 20 out of 180 patients were false negative (11.1\%), which means 20 patients faced the risk of complications of perforated appendicitis..

The overall specificity and sensitivity were found to be $84.8 \%$ and 83.3\% respectively, which showed that ultrasound has a relatively high specificity and sensitivity in diagnosing appendicitis especially with patients of normal weight. Our results compare well with other studies reported sensitivity $75 \%-98 \%$, specificity $86 \%-100 \%$ with positive and negative predictive values of $91 \%-100 \%$ and $89 \%-99 \%$ $[1,2,4,6,17,18]$.

In conclusion, ultrasound may be alongside clinical and laboratory testing to diagnose acute appendicitis. However, confirmatory tests such as CT may be needed in doubtful cases, especially in female patients and those with abnormal weight (overweight/ obese).

\section{References}

1. Birnbaum BA, Wilson SR. Appendicitis at the millennium. Radiology, 2000, 215:337-348.

2. Yacoe ME, Jeffrey RB Jr. Sonography of appendicitis and diverticulitis. Radiologic Clinics of North America, 1994, 32:899-912.

3. Annual report. Gaza, Palestine, Ministry of Health, 2005.

4. Ayaz A et al. Diagnostic accuracy of alvarado score in the diagnosis of acute appendicitis. Pakistan Journal of Medical Sciences, 2009, 25:118-121.

5. Balthazar EJ et al. Acute appendicitis: CT and ultrasound correlation in 100 patients. Radiology, 1994, 190:31-35.

6. Paulson EK, Kalady MF, Pappas TN. Suspected appendicitis. New England Journal of Medicine, 2003, 348:236-242.

7. Hoffmann J, Rasmussen OO. Aids in the diagnosis of acute appendicitis. British Journal of Surgery, 1989, 76:774-779.

8. Izbicki JR et al. [Retro- and prospective studies on the value of clinical and laboratory chemical data in acute appendicitis] Retro- und prospektive Untersuchung zur Wertigkeit klinischer und laborchemischer Daten bei der akuten Appendicitis. Der Chirurg, 1990, 61:887-894.

9. Mittlepunkt A, Nora PF. Current features in the treatment of acute appendicitis: an analysis of 1,000 consecutive cases. Surgery, 1966, 60:971-975.

10. Lewis FR et al. Appendicitis: a critical review of diagnosis and treatment in 1,000 cases. Archives of Surgery, 1975, 110:677684.
11. Pieper R, Kager L, Nasman P. Acute appendicitis: a clinical study of 1018 cases of emergency appendectomy. Acta Chirurgica Scandinavica, 1982, 148:51-62.

12. Doria AS et al. Ultrasound or CT for diagnosis of appendicitis in children and adults? A meta-analysis. Radiology, 2006, 241:83-94.

13. Keyzer $\mathrm{C}$ et al. Comparison of ultrasound and unenhanced multi-detector row CT in patients suspected of having acute appendicitis. Radiology, 2005, 236:527-534.

14. Lee SL, Walsh AJ, Ho HS. Computed tomography and ultrasonography do not improve and may delay the diagnosis and treatment of acute appendicitis. Archives of Surgery, 2001, 136:556-562.

15. Styrud J, Josephson T, Eriksson S. Reducing negative appendectomy: evaluation of ultrasonography and computed tomography in acute appendicitis. International Journal for Quality in Health Care, 2000, 12:65-68.

16. Fujii $Y$ et al. Ultrasonography improves diagnostic accuracy of acute appendicitis and provides cost savings to hospitals in Japan. Journal of Ultrasound in Medicine, 2000, 19:409-414.

17. Summa $M$ et al. Integrated clinical-ultrasonographic diagnosis in acute appendicitis. Journal de Radiologie, 2007, 10:175-178.

18. Franke $\mathrm{C}$ et al. Ultrasonography for diagnosis of acute appendicitis: results of a prospective multicenter trial. World Journal of Surgery, 1999, 23:141-146. 